\title{
High Spatial Resolution Time-of-Flight Secondary Ion Mass Spectrometry for the Masses: A Novel Orthogonal ToF FIB-SIMS Instrument with In Situ AFM
}

\author{
James A. Whitby, ${ }^{1}$ Fredrik Östlund, ${ }^{1,2}$ Peter Horvath, ${ }^{1}$ Mihai Gabureac, ${ }^{1}$ \\ Jessica L. Riesterer, ${ }^{1,3}$ Ivo Utke, ${ }^{1}$ Markus Hohl, ${ }^{2}$ Libor Sedláček, ${ }^{4}$ Jaroslav Jiruše, ${ }^{4}$ \\ Vinzenz Friedli, ${ }^{1,5}$ Mikhael Bechelany, ${ }^{1,6}$ and Johann Michler ${ }^{1}$ \\ ${ }^{1}$ EMPA, Swiss Federal Laboratories for Materials Science and Technology, Laboratory for Mechanics of Materials and Nanostructures, \\ Feuerwerkerstrasse 39, 3602 Thun, Switzerland \\ ${ }^{2}$ TOFWERK AG, Uttigenstrasse 22, 3600 Thun, Switzerland \\ ${ }^{3}$ Idaho National Laboratory, Idaho Falls, ID 83415, USA \\ ${ }^{4}$ Tescan a. s., Libušina třída 21, 62300 Brno, Czech Republic \\ ${ }^{5}$ Specs Zürich GmbH, Technoparkstrasse 1, 8005 Zürich, Switzerland \\ ${ }^{6}$ Institut Européen des Membranes (UR CNRS 5635), Université Montpellier 2, Place Eugène Bataillon, 34095 Montpellier, France
}

Correspondence should be addressed to James A. Whitby, james.whitby@empa.ch

Received 15 April 2011; Accepted 11 August 2011

Academic Editor: Adam Georg Balogh

Copyright ( $\odot 2012$ James A. Whitby et al. This is an open access article distributed under the Creative Commons Attribution License, which permits unrestricted use, distribution, and reproduction in any medium, provided the original work is properly cited.

We describe the design and performance of an orthogonal time-of-flight (TOF) secondary ion mass spectrometer that can be retrofitted to existing focused ion beam (FIB) instruments. In particular, a simple interface has been developed for FIB/SEM instruments from the manufacturer Tescan. Orthogonal extraction to the mass analyser obviates the need to pulse the primary ion beam and does not require the use of monoisotopic gallium to preserve mass resolution. The high-duty cycle and reasonable collection efficiency of the new instrument combined with the high spatial resolution of a gallium liquid metal ion source allow chemical observation of features smaller than $50 \mathrm{~nm}$. We have also demonstrated the integration of a scanning probe microscope (SPM) operated as an atomic force microscope (AFM) within the FIB/SEM-SIMS chamber. This provides roughness information, and will also allow true three dimensional chemical images to be reconstructed from SIMS measurements.

\section{Introduction and Design Philosophy}

The ion microprobe or secondary ion mass spectrometer (SIMS) has existed for almost fifty years $[1,2]$ but although great improvements have been made in sensitivity and ease of use, the lateral resolution has not improved quite as much. Early papers reported measurements from fifty micron areas for example, [2] but submicron image resolution using gallium liquid metal ion sources (LMIS) was reported even thirty years ago [3] and the separation of features as small as $20 \mathrm{~nm}$ wide has been reported $[4,5]$, close to the limits set by sensitivity $[4,6]$ and lateral ion straggling [7]. However, liquid metal gallium ion beams fell out of favour for SIMS because the limited secondary ion yields did not in general allow the full lateral resolution of the small ion beam spotsize to be used, and because many applications simply demanded more sensitivity - most easily achieved by using primary ions such as $\mathrm{Cs}^{+}$or $\mathrm{O}_{2}{ }^{+}$to improve the secondary ion yield by up to two orders of magnitude. That the effective spatial resolution in SIMS is often signal limited, especially so for liquid metal gallium ion sources, is well documented, for example, $[4,6,8]$. Nonetheless, the enormous increase in interest in nanomaterials over the last decade, and the limited spatial resolution of some common chemical analysis techniques such as electron-beam-induced X-ray emission (typically restricted to a information volume of about $1 \mu \mathrm{m}$ 
diameter by electron scattering) have prompted a new look at high spatial resolution SIMS $[9,10]$. A further motivation to re-examine the use of a gallium LMIS for SIMS is the increasingly widespread adoption of Focused Ion Beam (FIB) instruments for sample preparation (both milling and deposition). These almost universally use gallium LMIS beams to achieve excellent spatial resolutions with a high beam brightness (corresponding to acceptable milling speeds). The coupling of a secondary ion mass spectrometer to a dedicated FIB instrument has been previously described by others for example, $[5,11,12]$.

Advantages of the combination of a FIB/SEM with a SIMS include excellent sample imaging (secondary electrons from either electron or ion beams, the latter giving better channelling contrast) and positioning, and the use of the FIB to precisely expose buried regions of interest for further analysis by SIMS (and other techniques). It is far more common for FIB/SEM instruments to be designed from the start to accommodate extra analytical techniques such as EDX, EBSD, and cathodoluminescence. and these additional techniques which are complementary to SIMS can be decisive in answering analytical questions posed by complex samples. Having several types of analytical measurement possible with a single vacuum chamber is not only a great time and money saver, but also avoids uncertainty due to atmospheric contamination. The advantages of SIMS measurements over the EDX measurements more commonly found on FIB/SEM instruments are (i) better limits of detection (including fewer interferences for light elements), (ii) better spatial resolution, (iii) ability to make isotopic and molecular measurements. It is, however, more difficult in general to quantify SIMS measurements than is the case for EDX measurements on sufficiently large and thick materials.

In this paper, we describe an implementation of an FIBSIMS instrument and show examples of measurements made with the prototype. Our focus has not been upon the best possible SIMS performance, but rather upon a pragmatic, cost-effective approach to sub- $\mu \mathrm{m}$ resolution chemical imaging that take as its starting points a standard commercial FIB instrument and a tried and tested mass analyser design. The FIB-SIMS functionality was developed as part of the European Union funded FIBLYS (see http://www.fiblys.eu/) project which aims to create a modular suite of analytical instruments which can be fitted to an optimised FIB/SEM chamber. A consequence of the decision to use a commercial FIB/SEM instrument is that the vacuum chamber is only designed to work at high vacuum (above $10^{-6}$ mbar) rather than the ultrahigh vacuum usual for secondary ion mass spectrometers. The implications of this are discussed below in the performance section.

\section{The Instrument}

The FIB/SEM chamber, columns, and FIB/SEM software are commercially available parts from Tescan a.s. (a Vela SEM fitted with a FIB column using a liquid metal gallium ion source). The mass spectrometer is a commercial orthogonal extraction time-of-flight instrument from Tofwerk AG (model C-TOF) with a $0.5 \mathrm{~m}$ nominal drift length, including

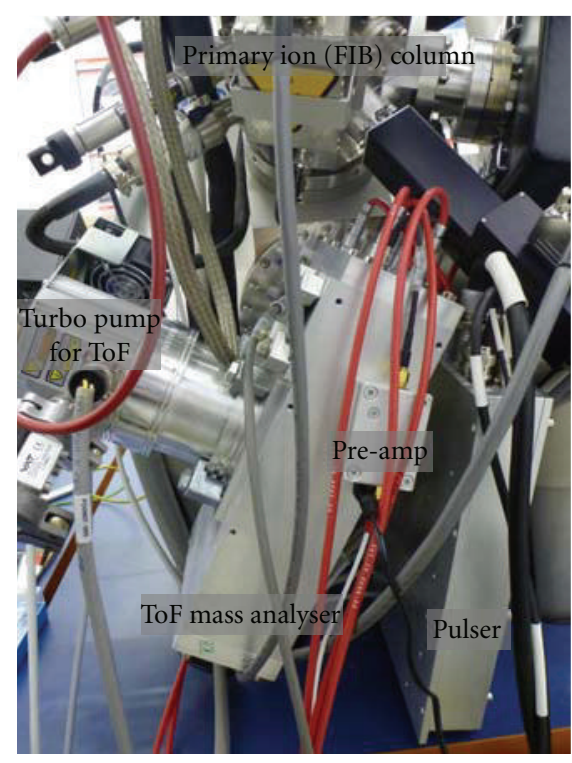

FIGURE 1: A closer look at the mass analyser in position on the back of the chamber; there is very little space available. The turbo pump on the mass analyser (to protect the detector) will be replaced by an ion pump. The pulser electronics for the orthogonal extraction are placed close to the mass analyser in order to preserve the pulse shape.

the reflectron. This mass spectrometer was chosen because of its compact dimensions (see Figures 1 and 2) and because of the performance advantages and price/performance ratio of time-of-flight mass analysis compared to quadrupole mass analysis (as the samples expected to be studied by FIB-SIMS instruments are often very small and unique, the simultaneous detection of all masses in a time-of-flight instrument offers efficiency gains compared to scanning a quadrupole filter). Because of the small size of the instrument, the mass resolving power $M / \Delta M$ (FWHM) is no more than 800 at $69 \mathrm{Th}$, just sufficient to distinguish many molecular interferences from isobaric monatomic ions (Th denotes the unit Thomson for charge to mass ratio [13]). Orthogonal extraction [14], typically using a $2 \mu$ s pulse, provides a high effective duty cycle and more importantly avoids the need to pulse the primary beam (for TOF operation) or to use monoisotopic gallium (necessary to preserve mass resolution when pulsing the primary beam to define the TOF start signal), thus no changes to the FIB hardware are necessary. Secondary ions are detected in the mass spectrometer using a pair of chevron mounted microchannel plates (Photonis) and the resulting analogue signal passed through a preamplifier, an amplifier/constant fraction discriminator (RoentDek ATR19-2) and time-todigital converter (Cronologic GmbH HPTDC8-PCI) before being passed to computer memory. Essentially the same model of mass spectrometer has been previously described in more detail in [15] for a similar application, although in the current implementation all hardware is from Tofwerk AG. Either positive or negative secondary ions can be detected, but not simultaneously. The postacceleration voltage towards 


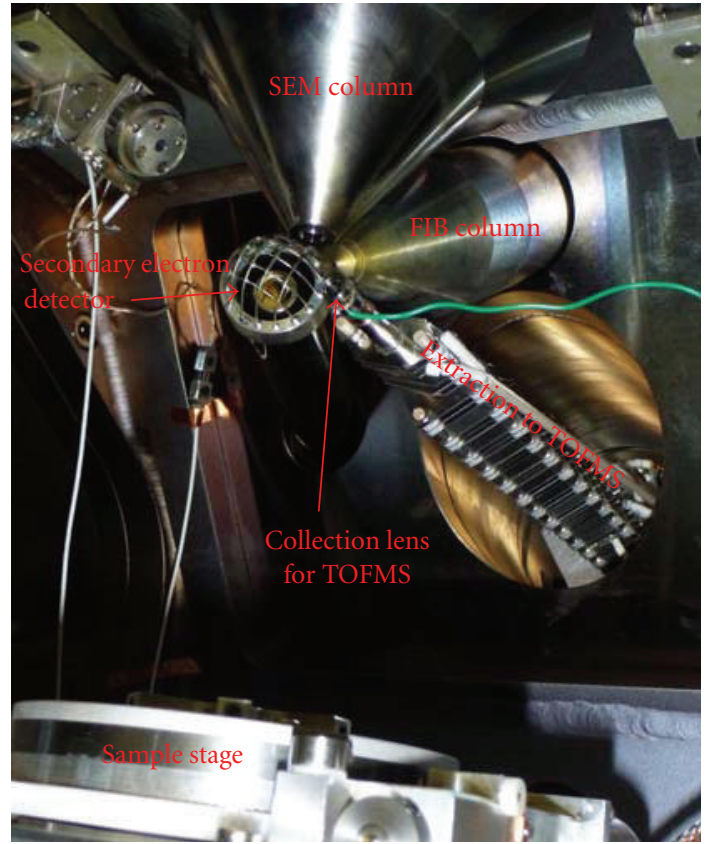

Figure 2: Interior of FIB/SEM-SIMS prototype. The sample stage has been lowered to make the arrangement of the collection lens and charged particle columns clearer. For SIMS work, the sample is usually positioned at a working distance of $9 \mathrm{~mm}$ below the SEM column, and tilted to $55^{\circ}$ to present the sample surface normal to the incident gallium ions. Additional instrumentation such as nanomanipulators, gas injection systems, and EDX or BSE detectors can be added as required. For SPM measurements, the SPM assembly was mounted on the sample stage.

the microchannel plate detector is typically $5 \mathrm{kV}$, high enough to still give detection efficiencies of about $20 \%$ for ions with masses up to $2000 \mathrm{Da}$ [16].

In order to make secondary ion measurements possible, collection and transfer ion topics were designed and built to take ions from the sample to the mass analyser (mounted on a flange of the FIB/SEM chamber). A set of Einzel lenses acting as relay lenses is used to transmit ions from the collection optics to the mass analyzer; all potentials are below $200 \mathrm{~V}$. A grounded shroud around the collection lens is used to improve collection efficiency and to minimize electrostatic disturbance to other instruments in the chamber. When SIMS measurements are not required, the front part of the extraction ion optics nearest the sample and pole pieces simply clips off (labelled "collection lens" in Figure 2), thus allowing the full range of sample sizes to be used by the FIB. For SIMS operation, it is advantageous to extend the ion optics so that the entrance aperture is nearer to the sample and ion beam: in the current design, the collection optics extend to within $8 \mathrm{~mm}$ of the sample/primary ion beam intersection. This leaves enough space for simultaneous operation of the SIMS functionality with a scanning probe microscope or gas injection system (e.g., for focused ion beam induced processing).

To collect mass spectra, software was written to (i) control the functions of the mass spectrometer, (ii) to initiate an appropriate scan series by the FIB, and (iii) to collect secondary electron images in parallel with the secondary ion mass spectra. The same software is used to view and analyse the mass spectra and to export the results in other formats (as ion images, mass spectra from selected regions, or raw data). All data are stored using the publicly available HDF5 file standard [17] which is supported by many data analysis packages such as Matlab, IDL, and Igor Pro. The TOF-SIMS software is, for performance reasons, hosted on a separate computer to that which controls the FIB/SEM. The two computers communicate via Tescan proprietary protocols using an Ethernet connection. Custom electronics and a timer card from National Instruments (model NI6602) are used to adapt hardware signals from the FIB/SEM (e.g., level shifting, logic operations, resynchronisation of clock cycles) in order to control the time-to-digital converter card and mass spectrometer extraction pulser.

During operation, the user uses the FIB/SEM to locate the point of interest and to adjust focus and magnification. Then, the desired image resolution, dwell time (mass to charge range) and number of frames are selected on the computer hosting the mass spectrometer software and the measurement is started from the latter. All triggers from the subsequent acquisition series are generated by the FIB/SEM instrument until the predetermined number of frames has been reached or the measurement is stopped manually. The FIB beam remains at each point in a frame for the defined dwell time before rapidly moving to the next point. The beam is not blanked during the move between neighbouring points, but between lines and frames it is. Although the SIMS capability has only been tested with FIB/SEM instruments from Tescan, it should be possible to fit the mass analysis hardware into instruments from other manufacturers, but the software and signalling interfaces might have to be modified. Example results and different ways of displaying the data are shown in Figures 4, 5, and 6 for a nickel finder grid.

A note on nomenclature: we refer to one complete $x-y$ raster of the primary beam when collecting SIMS data as a "frame". Each frame is composed of data from an evenly spaced Cartesian grid of points projected onto the sample surface. From each of these points, one mass spectrum is obtained from one extraction cycle of the TOFMS. Because dynamic SIMS implies sputtering, we may consider each measurement point as having some depth, and thus being a volume element or voxel. These are referred to as "raw voxels". In practice, because the number of ions detected per raw voxel is rather low, these raw voxels are binned into "effective voxels" for visualization although the raw data is kept. It should be noted that SIMS measurements alone do not provide depth information, thus the use of "voxel" might be argued with. The meaning of "depth profile" and "chemical image" is illustrated in Figure 3.

\section{Performance}

Experience with this design of mass spectrometer suggests that the dynamic range of the instrument is limited by internal ion scattering to about eight decades (implying $10 \mathrm{ppb}$ detection limits if all secondary ions were produced with the 


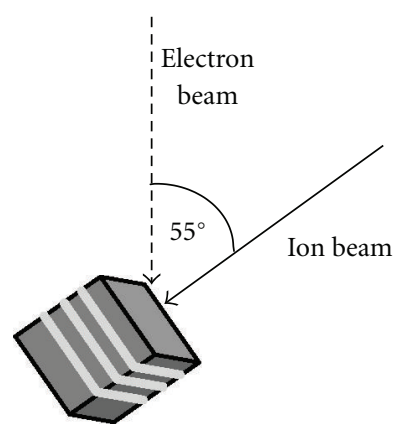

"Depth profile"

(planar structures normal to ion beam)

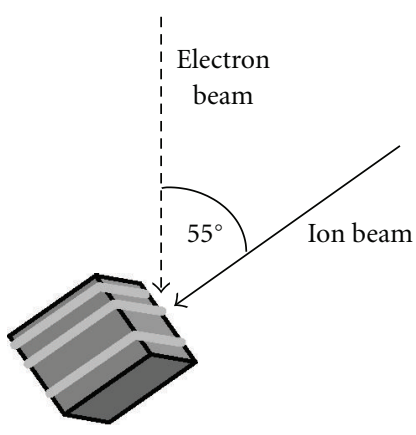

"Image"

(planar structures parallel to ion beam)

FIGURE 3: Clarification of the primary ion beam and sample orientation for the BAM L200, VCSEL, and ALD samples described in the text, all of which have planar structures. Depth profiles are reconstructed using the middle quarter of each image slice ("frame") in order to minimise edge effects. The resolution in the ion beam direction (depth resolution) is limited only by ion-induced mixing and roughening and redeposition/edge effects and is in general better than the resolution in the directions normal to the ion beam (lateral resolution) which depends heavily on the spot size and shape.
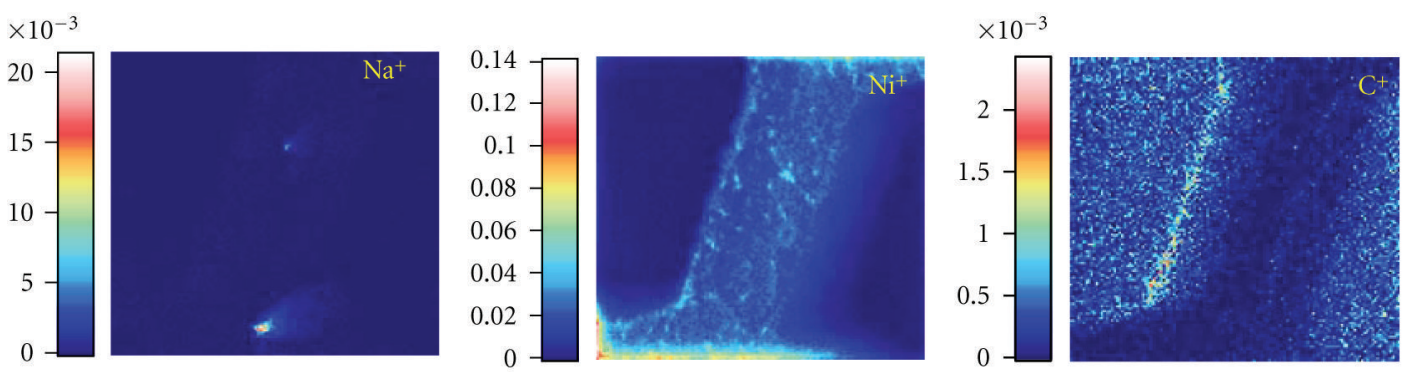

FIGURE 4: Secondary ion images for sodium, nickel, and carbon from part of a nickel finder grid on an adhesive carbon patch. Field of view is $20 \times 20$ microns. Oxygen flooding was used to enhance the nickel signal. Because the full dataset is three dimensional, it could be shown that the sodium signal was only present at the surface of the sample. The colour scale intensity units are ions per raw voxel $(1024 \times 1024 \times$ 178 ); for display purpose the data has been binned to $128 \times 128 \times 178$ ).

same useful yield). In practice, for most samples integration times sufficient to make $10 \mathrm{ppb}$ peaks clear above the scattered ion background are impractical using primary ion currents suited to submicron resolution imaging $(<200 \mathrm{pA})$. Figure 6 shows in excess of six decades of dynamic range, and Figure 7 shows a calibration curve for boron in silicon from which a limit of detection of $5.5 \mathrm{ppm}$ is inferred. The limit of detection is a strong function of the secondary ion yield, so it will vary for different secondary ions and matrices.

The useful ion yield was calculated for aluminium secondary ions from a distributed Bragg reflector (DBR) structure consisting of alternating $\mathrm{AlGaAs}$ and GaAs layers of known thickness (see Figure 12), and a figure of $4 \times$ $10^{-6}$ detected ions per sputtered atom was obtained using a primary ion energy of $20 \mathrm{keV}$. We are not aware of a comparable useful yield measurement in the literature for the same material and primary ion beam. It is well known that secondary ion yields vary enormously with the ion and matrix (as well as primary ion element, energy, and incident angle) and surface quality. Useful ion yields are further dependent upon the tuning of the mass analyser and extraction optics (it is for example common practice to use an energy filter to suppress polyatomic ions despite the resulting reduction in useful ion yield for the analyte ions); a comparison to the (sparse) literature is, therefore, somewhat difficult. Reported values for useful ion yields for gallium ion SIMS include $1.4 \times 10^{-2}$ for $\mathrm{Si}^{+}$from silicon oxide, $6 \times$ $10^{-5}$ for $\mathrm{Si}^{+}$from silicon, $1.93 \times 10^{-3}$ for $\mathrm{In}^{+}$from indium phosphide and $7.8 \times 10^{-6}$ for $\mathrm{P}^{+}$from indium phosphide $[18,19]$. Bearing in mind that aluminium ions seem to be detected more sensitively than most on our instrument and that the chamber pressure is always above $4 \times 10^{-6} \mathrm{mbar}$ (and so some signal enhancement due to oxygen possible) and there is a suggestion that the observed useful ion yield could be improved. We did not use silicon or silicon dioxide to calculate a useful ion yield, because it was not possible to obtain a stable signal under normal conditions at the pressure used in the instrument described here. The implications of high vacuum operation of a SIMS instrument (instead of ultrahigh vacuum) are discussed below.

Chemical images in which lines spaced by less than $100 \mathrm{~nm}$ are separated have been obtained (see Figures 9 and 13), and we are certain that this figure can be improved upon in future by better focussing of the FIB beam. The depth resolution can be, as expected, much better than $20 \mathrm{~nm}$; see Figure 15. 


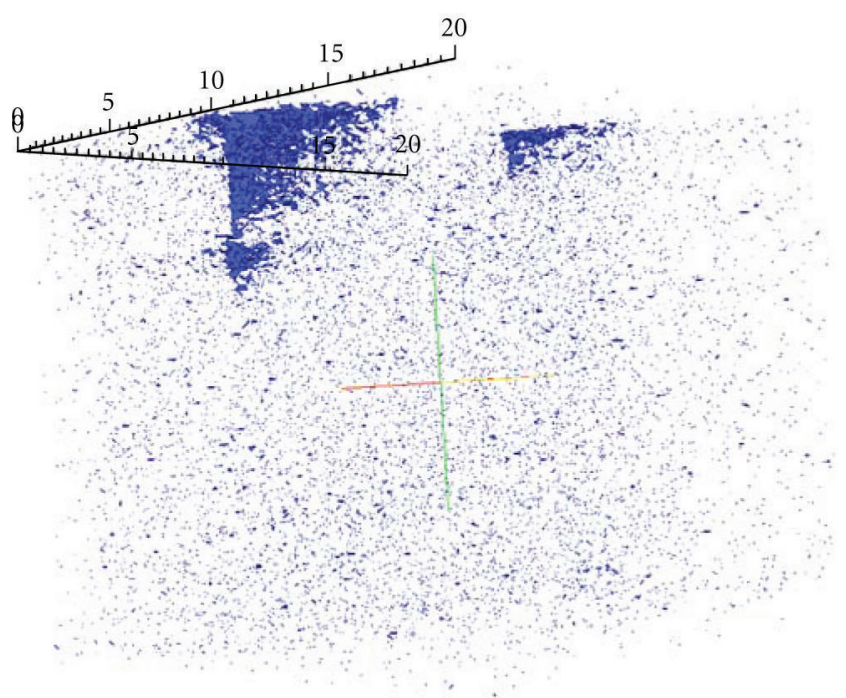

Figure 5: Three-dimensional display of sodium secondary ions from the nickel finder grid shown in Figure 4. It can be seen that the sodium is concentrated in two locations, both at the surface of the sample. The tailing in the $\mathrm{z}$ direction may be due to the shape of the sodium deposit on the nickel grid or may also be in part due to ion-beam-induced roughening and mixing. The $x$ and $y$ dimensions are $20 \mu \mathrm{m}$ as for Figure 4; the $z$ dimension is unknown, but is orders of magnitude less than this. The view is of isointensity surfaces after thresholding to remove background counts.

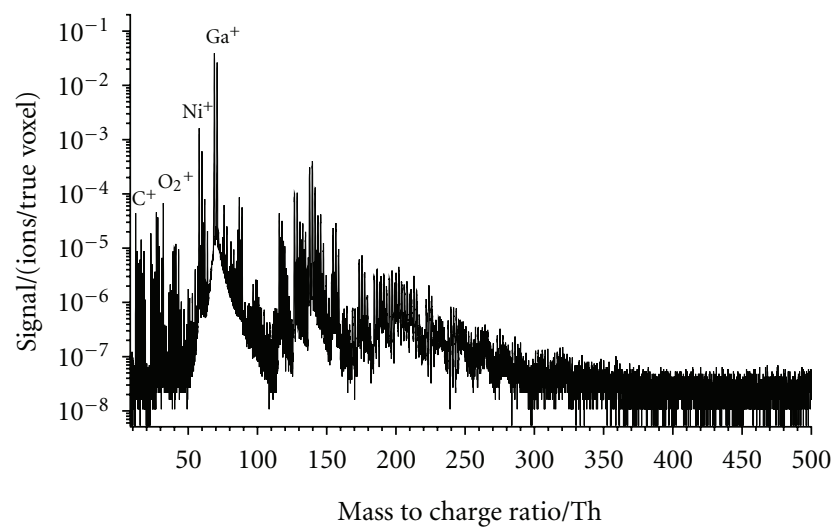

Figure 6: Mass spectrum from nickel finder grid on adhesive carbon patch (see also Figure 4). About six decades of dynamic range are exhibited by this spectrum. Note the relatively large molecular oxygen peak due to the use of oxygen flooding to enhance the nickel ion signal.

Mass Discrimination. The gallium isotope ratio from a GaAs target (so the gallium signal consists of secondary ions from both the sample and from implanted primary ions) was measured as $1.46 \pm 0.02$, the literature value is $1.507 \pm$ 0.0004 [20]. Mass discrimination is therefore of the order of $15 \%$ Da for this example. Similar magnitudes for the mass discrimination have been observed for iron and nickel from metal alloys.

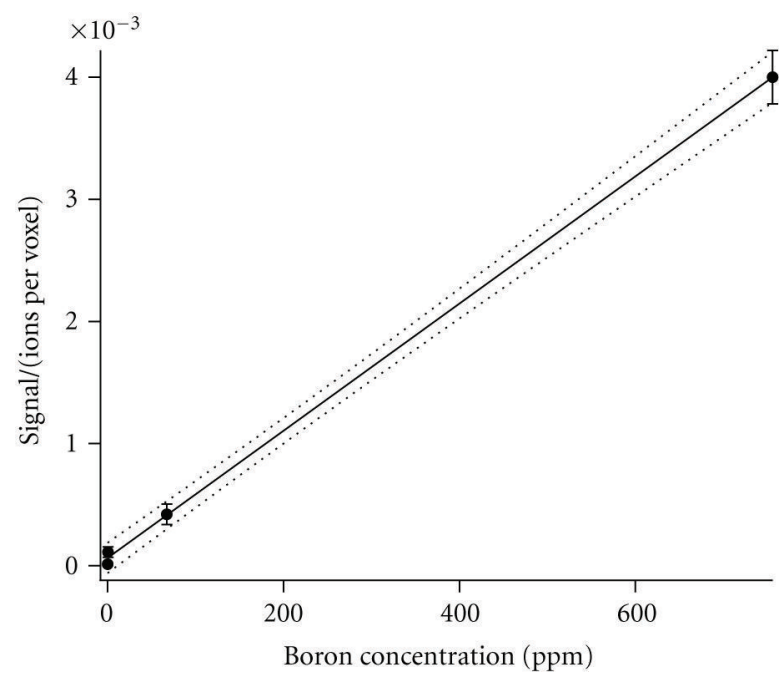

Figure 7: Calibration plot for boron in doped silicon wafers showing a linear fit to the measured points (three standards and one blank), and 95\% confidence limits. An oxygen partial pressure of $6.0 \times 10^{-5}$ mbar was used to enhance the signal; the primary beam was $30 \mathrm{keV},>14.7 \mathrm{nA}$ with a scan area of 10 by $10 \mu \mathrm{m}$ (the current cannot be measured above $14.7 \mathrm{nA}$ ). The limit of detection under these conditions for this material was $5.5 \mathrm{ppm}$.

Mass Resolution and Abundance Sensitivity. The measurements reported here were obtained using a mass resolving power of $M / \Delta M$ (FWHM) of $400 \mathrm{Th} / \mathrm{Th}$ at mass to charge ratio $69 \mathrm{Th}$. The abundance sensitivity was $2.5 \times 10^{-5}$.

3.1. Effect of Chamber Pressure. Commercial FIB/SEM instruments are mostly designed to work at high vacuum rather than ultrahigh vacuum, and this has several consequences when performing secondary ion measurements in such an instrument.

(i) Because secondary ion yields depend upon the partial pressure of for example, oxygen (e.g., [21]), there will be a change in sensitivity (drift) as the instrument pumps down after opening the chamber, for example, to change samples. The presence of oxygen in conjunction with ion beam sputtering can complicate the appearance of oxide interfaces [22].

(ii) Even at the lowest pressure the chamber can attain ( $\left.>1 \times 10^{-6} \mathrm{mbar}\right)$, there will be a sufficient partial pressure of chemically active gases (e.g., water and oxygen) to affect the secondary ion yield for some materials $[23,24]$. This may improve sensitivity, but complicates comparison of useful yields to published values. See Figure 8 for an example of this effect.

(iii) The absorption of chamber gases onto the sample surface contributes a background to the secondary ion mass spectrum, and causes a nonlinear dependence of the SIMS signal upon the primary beam current and scan area $[25,26]$.

(iv) The presence of active gases changes the extent to which surfaces roughen under ion bombardment. 


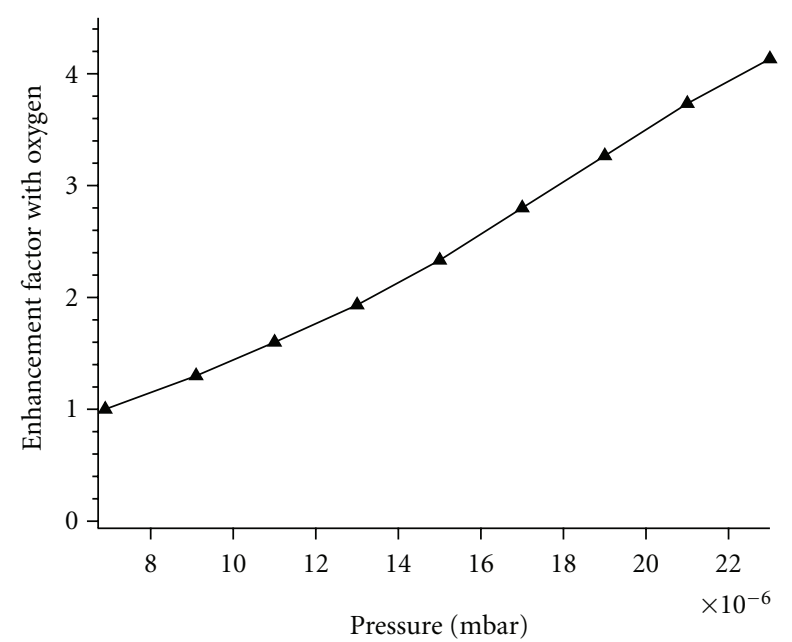

Figure 8: Effect of oxygen flow rate on SIMS signal for a cobalt alloy; the graph shows the $\mathrm{Co}^{+}$secondary ion signal as oxygen was bled into the chamber through a needle valve. The plot has been normalised to the signal when the needle valve was closed (i.e., no oxygen flow, chamber pressure $6.9 \times 10^{-6}$ mbar). $5 \mathrm{keV}, 1270 \mathrm{pA}$ $\mathrm{Ga}^{+}$primary beam, $10 \times 10 \mu \mathrm{m}$ scan area. It can be seen from the gradient that there is likely a significant oxygen enhancement effect for cobalt secondary ions even at the lowest pressure (with no oxygen flow).

All of these effects may be minimised (but not avoided completely) by venting with an inert gas or better by using a load-lock chamber. Normalisation to the gallium ion signal can sometimes be used to correct for oxidation effects on SIMS yields [27]. In general, however, for good reproducibility it is necessary to record (and to control) the pressure in the chamber when performing SIMS measurements at high vacuum. For samples which are sensitive to the residual gases in the chamber (e.g., silicon), we suggest deliberately adding a known partial pressure of for example, oxygen in order to improve stability. Oxygen flooding can however have sideeffects such as distortion of depth profiles [24].

\section{Applications}

To illustrate the performance of our first FIB-SIMS prototype, we present here some example applications. When an image is captioned as a depth profile, it means that the data has been integrated from a region of each $x-y$ plane (frame) and is plotted as a function of frame number (equivalent to depth or $z$-direction). When an image is captioned as an "image", it means that the $x-y$ (frame) data is shown, and that the data has been integrated along the $z$ /depth direction. See also Figure 3. For all of the data shown here, the primary ion beam was incident normal to the mean sample surface. Depth profiles use only the centre part of each frame in order to minimise crater edge effects (this conservative approach throws away $75 \%$ of the signal).

4.1. Spatial Resolution Standard BAM L200. Figure 9 shows an aluminium secondary ion image from an unmounted,

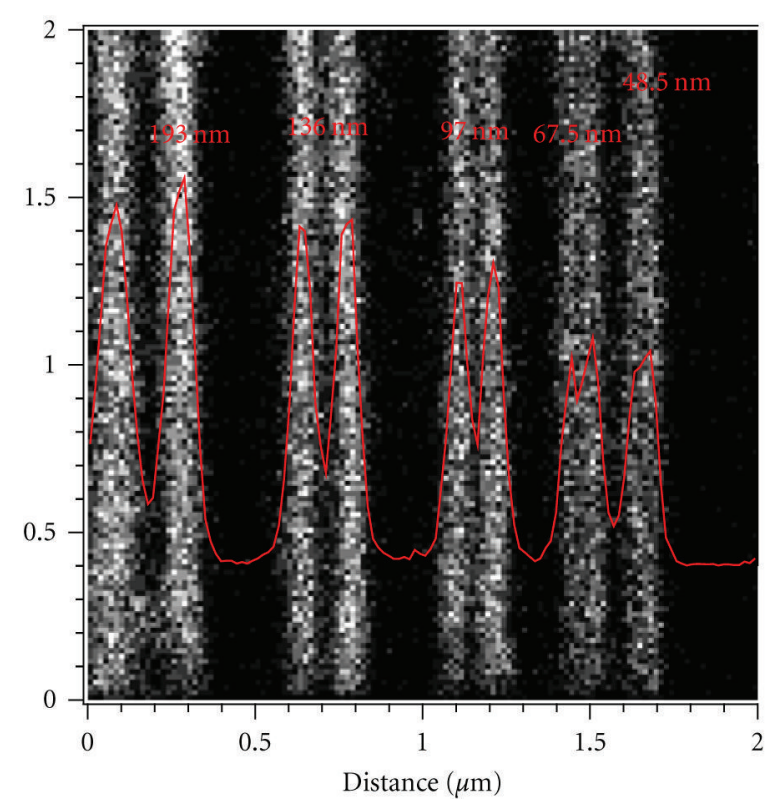

FIGURE 9: Aluminium secondary ion image from the BAM L200 aluminium/indium/gallium arsenide standard. Field of view $2 \times$ $2 \mu \mathrm{m}$, displayed pixel size $15.6 \mathrm{~nm}, 30 \mathrm{keV},<1 \mathrm{pA}$ primary gallium ion beam. Superimposed in red are the integrated profile, and labels denoting the period of each line pair (see bam_1200repe.pdf from http://www.rm-certificates.bam.de/ for more information). The $67.5 \mathrm{~nm}$ period line pair (i.e., lines of width $34 \mathrm{~nm}$, separated by $34 \mathrm{~nm}$ ) is barely split, but the $97 \mathrm{~nm}$ period pair ( $49 \mathrm{~nm}$ wide lines) is well resolved.

unpolished chip of the BAM L200 resolution test reference material. BAM define the spatial resolution to be that of the smallest period grating that can be distinguished, in this case P7 with period $67.5 \mathrm{~nm}$ (the widths and separation of the aluminium rich stripes in $\mathrm{P} 7$ are $34 \mathrm{~nm}$ ). The ion beam FWHM is calculated to be about $50 \mathrm{~nm}$ (see below). Noteworthy is that the chemical image was achieved from a rather rough surface-the existence of surface topography (scratches from sawing the sample) did not distort the chemical image. It was also possible to detect (but not resolve) the single aluminium rich stripes W8 (38 nm), W5 (19. nm) W10 $(14.2 \mathrm{~nm})$ and W9 $(3.6 \mathrm{~nm})$. In a round-robin study of SIMS resolution [10] only ten out of sixteen laboratories could detect a $5 \mathrm{~nm}$ wide aluminium rich stripe in the similar BAM L002 standard, and the smallest calculated beam FWHM was $69 \mathrm{~nm}$.

Figure 10 shows the corresponding indium ion image. The signal here is nosier both because indium is less sensitively detected than aluminium from this material and because the indium-rich stripes are very thin $(<5 \mathrm{~nm}$, much smaller than a single pixel in this image).

The lateral resolution of an image can be defined in various ways, as discussed by [28] and will, in general, depend also upon the signal to noise ratio of the image. The ISO definition for surface chemical analysis makes reference to the distance between the $12 \%$ and $88 \%$ intensity points in a line scan across a well-defined step function [29]. 


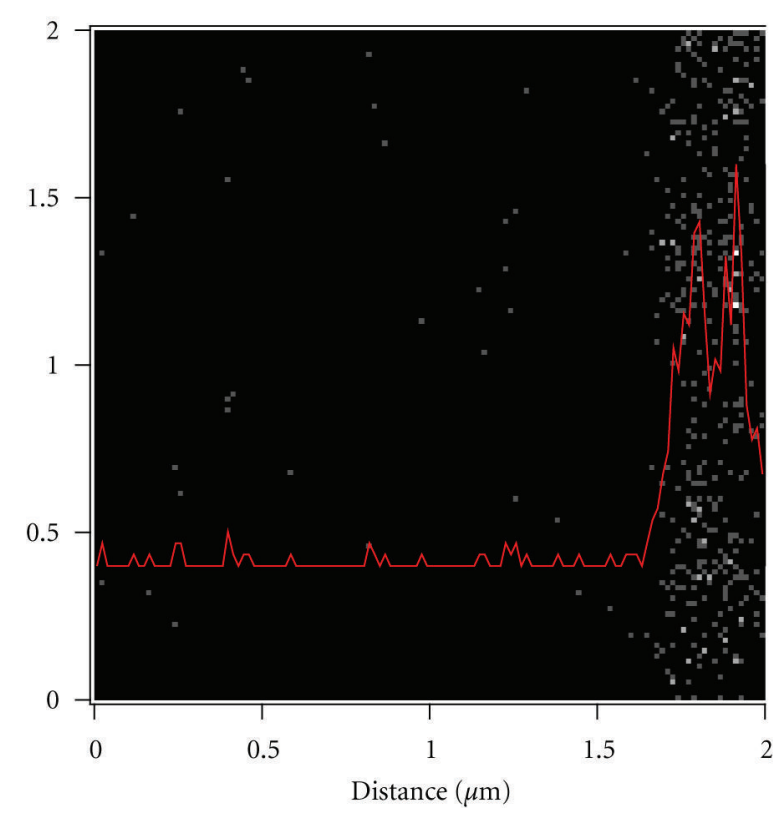

FIgURe 10: Indium positive secondary ion image from BAM L200 (same data set as Figure 9). The unresolved indium features actually consist of two line pairs (each with $5 \mathrm{~nm}$ wide indium rich lines) the distance between the line pairs is not documented.

For a Gaussian beam, a good approximation to gallium LMIS beam spot distributions [10], this distance corresponds to the full width at half-maximum (FWHM). Note that some FIB manufacturers prefer to use the $20 \%$ and $80 \%$ intensity points. Figure 11 shows the result of fitting the complementary error function (the convolution of a Gaussian with a step function) to part of the aluminium profile shown in Figure 9. The aluminium rich stripe in $\mathrm{P} 4$ has a width of $97 \mathrm{~nm}$; just large enough compared to the spot size to regard the profile as a measured edge spread function. A reasonable fit is obtained suggesting that the beam profile is well approximated by a Gaussian distribution. Using either the ISO definition or a deconvolution of the data gives a FWHM for the primary beam of about $50 \mathrm{~nm}$ (the $20 \%-80 \%$ definition gives a spot size of about $40 \mathrm{~nm}$ ). With experience, we expect further increases in performance, as according to the manufacturer it should be possible to obtain this beam size at much higher currents than we used (the specification is for $50 \mathrm{pA}$ into a $20 \mathrm{~nm}$ spot, or $500 \mathrm{pA}$ into a $50 \mathrm{~nm}$ spot).

The above analysis assumes that the resolution is determined by the primary beam size and not by any other physical processes. We can neglect lateral straggling of primary ions as this is of the order of a few nanometers [7], possibly up to $20 \mathrm{~nm}$ [9]. Although differential sputtering and the resulting increase in rugosity of the surface might contribute to a larger effective spot size, because secondary ion yields depend on surface roughness and the surfaceprimary beam angle, we do not see any change of lateral resolution with depth.

4.2. Semiconductor Laser. The performance achieved with the BAM L200 standard is particularly relevant to applica-

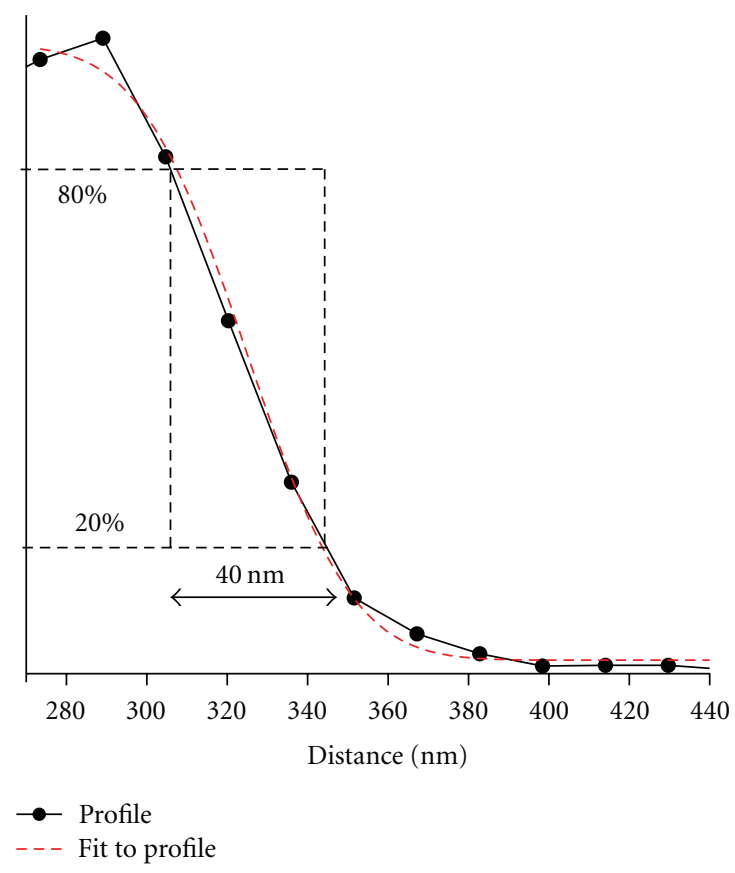

FIGURE 11: Enlargement of part of the profile from Figure 9 showing a superimposed fit of a complementary error function and the $20 \%$ and $80 \%$ points. The inferred spot size for the FIB beam (and so the spatial resolution of the SIMS signal) is between 40 and $50 \mathrm{~nm}$ for this dataset.

tions involving semiconductor or photonic devices fabricated in gallium arsenide. Figures 12 to 14 show depth profiles and chemical images of a Vertical Cavity Surface Emitting Laser constructed from an AlGaAs/GaAs Distributed Bragg Reflector (DBR) fused to an AlGaInAs/InP gain wafer. The device has been previously described in more detail in [30] and was the first example of a wafer-fused semiconductor disk laser operating at the $1.3 \mu \mathrm{m}$ wavelength. The specimen described here is denoted VECSEL 3/1. Figure 12 shows a positive secondary ion depth profile through the device. On the right hand side is part of the AlGaAs/GaAs DBR structure ( 35 repeats of a $100 \mathrm{~nm}$ layer of GaAs and a $100 \mathrm{~nm}$ layer of $\mathrm{Al}_{0.9} \mathrm{Ga}_{0.1} \mathrm{As}$ ). On the left-hand side (left of frame 70 on the $x$-axis) are the structures in the AlGaInAs/InP wafer. The expected structure is shown schematically in Figure 13. Although much of the compositional structure of the device is visible, the structure within the five quantum well regions was not resolved. (Each of these $44 \mathrm{~nm}$ thick units consists of three $10 \mathrm{~nm}$ thick $\mathrm{Al}_{0.28} \mathrm{Ga}_{0.26} \mathrm{In}_{0.46}$ As layers separated by two $7 \mathrm{~nm}$ thick layers of $\mathrm{Al}_{0.14} \mathrm{Ga}_{0.18} \mathrm{In}_{0.68} \mathrm{As}$; each unit is then spaced apart by InP layers). The depth resolution in this profile is apparently of the order of $20 \mathrm{~nm}$. As reported previously for a SIMS depth profile of a similar material [31] using different experimental conditions, we see a decrease in the modulation depth of the repeated layers with depth (i.e., the peak to valley difference of the aluminium signal) which was shown to be due to roughening of the surface (ripple formation [31]). The effect is less severe for the conditions reported here, consistent with the lower extent of 
SIMS depth profile (positive ions) of VCSEL sample from EPFL $20 \mathrm{keV}, 500 \mathrm{pA} \mathrm{Ga}^{+}$primary ions, $10 \times 10$ micron scan area
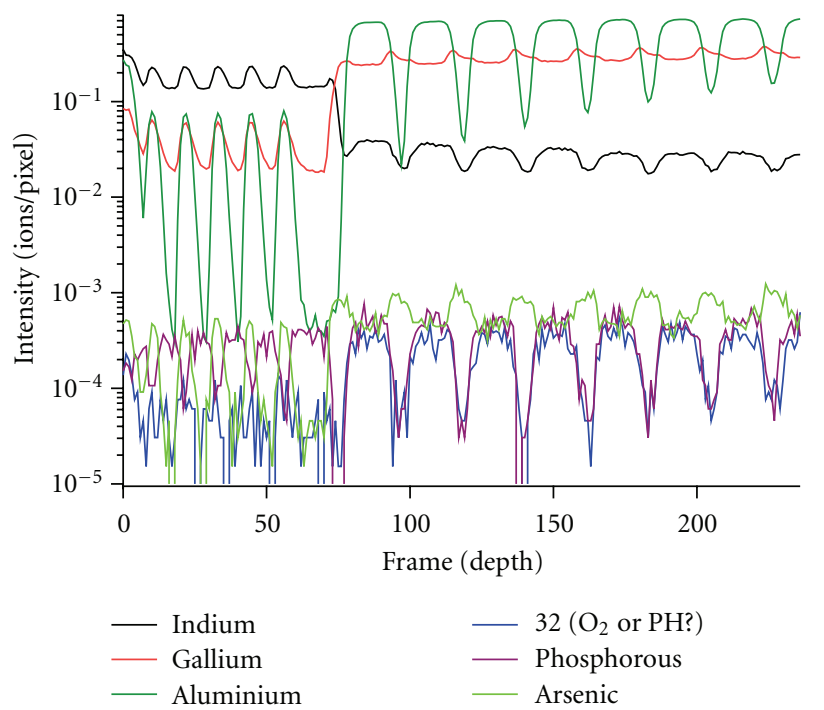

FIGURE 12: Depth profile of VECSEL 3/1 (see text). The well resolved aluminium features on the right hand side of the figure are each $100 \mathrm{~nm}$ in width and $100 \mathrm{~nm}$ apart. Similar results were achieved using a range of primary ion energies and currents. The modulation depth of the gallium signal is restricted because of the use of a gallium ion primary beam, which necessarily results in a strong gallium secondary ion background signal (due to secondary ions from implanted gallium).

roughening as measured by scanning probe microscopy (see section below).

Figure 13 shows the same structure, but in a different experiment viewed from the side. The $100 \mathrm{~nm}$ thick aluminium stripes in the DBR are clearly separated from each other, but do not have flat tops, and the modulation depth is only about $80 \%$, so the resolution in this image is a little better than $100 \mathrm{~nm}$.

That the FIB-SIMS cannot only visualise expected chemical structures, but also reveal new information, is shown in Figure 14. This overlay of depth profiles obtained from both positive and negative secondary ions shows an unexpected small peak in the oxygen ion signal at frame 60-this is very close to the wafer interface and suggests that a surface oxide layer may have been incorporated during the wafer fusion process.

4.3. Atomic Layer Deposition Fabricated Multilayers. Atomic layer deposition (ALD) is a coating technique using selflimiting surface reactions of alternately supplied volatile precursor molecules to make highly conformal films with excellent control of thickness [32], almost to single atomic layers. Conformal ALD coatings have been used for example to coat nanopillars for novel applications in photovoltaic materials and nanomechanics, as well as to make transparent conductive oxide films. Zinc oxide has potential as a semiconductor material for optoelectronics, and aluminium-doped zinc oxide can be used as a thin transparent conducting oxide (TCO) film. The FIB-SIMS was used to investigate ALD multilayers of zinc oxide and aluminium oxide that were prepared as part of a study into their photoelectric properties, and in particular to study some fundamental characteristics of the ALD produced materials.

The films were produced at EMPA in a home-made reactor using dimethyl zinc (95\% purity from STREM Chemicals, Inc.), trimethyl aluminium (97\% purity from SigmaAldrich Co.) and water vapour as reagents, and argon as a carrier gas. The substrate was (111) silicon carefully cleaned to remove organic contaminants from the surface. The deposition was carried out at $65^{\circ} \mathrm{C}$ with the following cycle times: $0.1 \mathrm{~s}$ pulse, $20 \mathrm{~s}$ exposure, and $45 \mathrm{~s}$ purge. A $20 \mathrm{~nm}$ thickness of $\mathrm{Al}_{2} \mathrm{O}_{3}$ required 154 cycles and a $20 \mathrm{~nm}$ thickness of $\mathrm{ZnO}$ required 100 cycles. Figure 15 shows a FIBSIMS depth profile through five pairs of nominally $20 \mathrm{~nm}$ zinc oxide and $20 \mathrm{~nm}$ aluminium oxide layers on a silicon substrate. All of the layers are clearly seen in the depth profile and the aluminium signal shows a "top-hat" profile suggesting that the depth resolution in aluminium oxide is much better than $20 \mathrm{~nm}$. However, the modulation depth of the aluminium signal is poor and the zinc signal does not have a "top-hat" profile. Figure 16 shows that the zinc oxide layers are actually thinner than the aluminium oxide layers, furthermore we expect the zinc oxide layers to be sputtered faster. As a result, the zinc oxide layers although clearly visible are not thick enough to give a "top-hat" profile. It is not clear why the zinc signal from the uppermost layer (and to a lesser extent the aluminium signal too) is so much stronger than for subsequent layers. We suspect that this is a result of adsorbed atmospheric constituents (molecular oxygen, water) in the ALD material. The signature is probably not simply due to a build up to the equilibrium concentration of implanted gallium, because it does not repeat at each subsequent interface. (For $20 \mathrm{keV}$ primary ion energy, we do observe repeated structure in the SIMS depth profile within each aluminium oxide layer; this structure is believed to be a measurement artefact. SIMS measurements at interfaces can be complicated because sputtering can cause chemical changes (e.g., reduction) in the sample material at the same time that the implanted ion dose and damage approach a steady state [22]). The high signal for the mass to charge ratio $28 \mathrm{Th}$ between the last aluminium oxide layer and the silicon substrate is due to chemistry at the substrate interface resulting in (i) either a stronger $\mathrm{AlH}^{+}$ion signal (which interferes strongly with ${ }^{28} \mathrm{Si}^{+}$, and in practice dominates in this sample) or (ii) a stronger ${ }^{28} \mathrm{Si}^{+}$signal due, for example, to the presence of a thin layer of silicon oxide. Isotope ratios suggest that the latter explanation (enhancement of silicon secondary ion signal at the interface) is more likely. An unexpected observation was that of a weak boron signal (see Figure 17), correlating with the zinc oxide layers. The presence of boron in ALD fabricated zinc oxide layers was subsequently confirmed by glow discharge optical emission spectroscopy (GD-OES), and was found to be due to an impurity in the zinc precursor.

Limiting Depth Resolution of SIMS. Secondary ions come from very near the surface $(<0.5 \mathrm{~nm})$ and the depth 


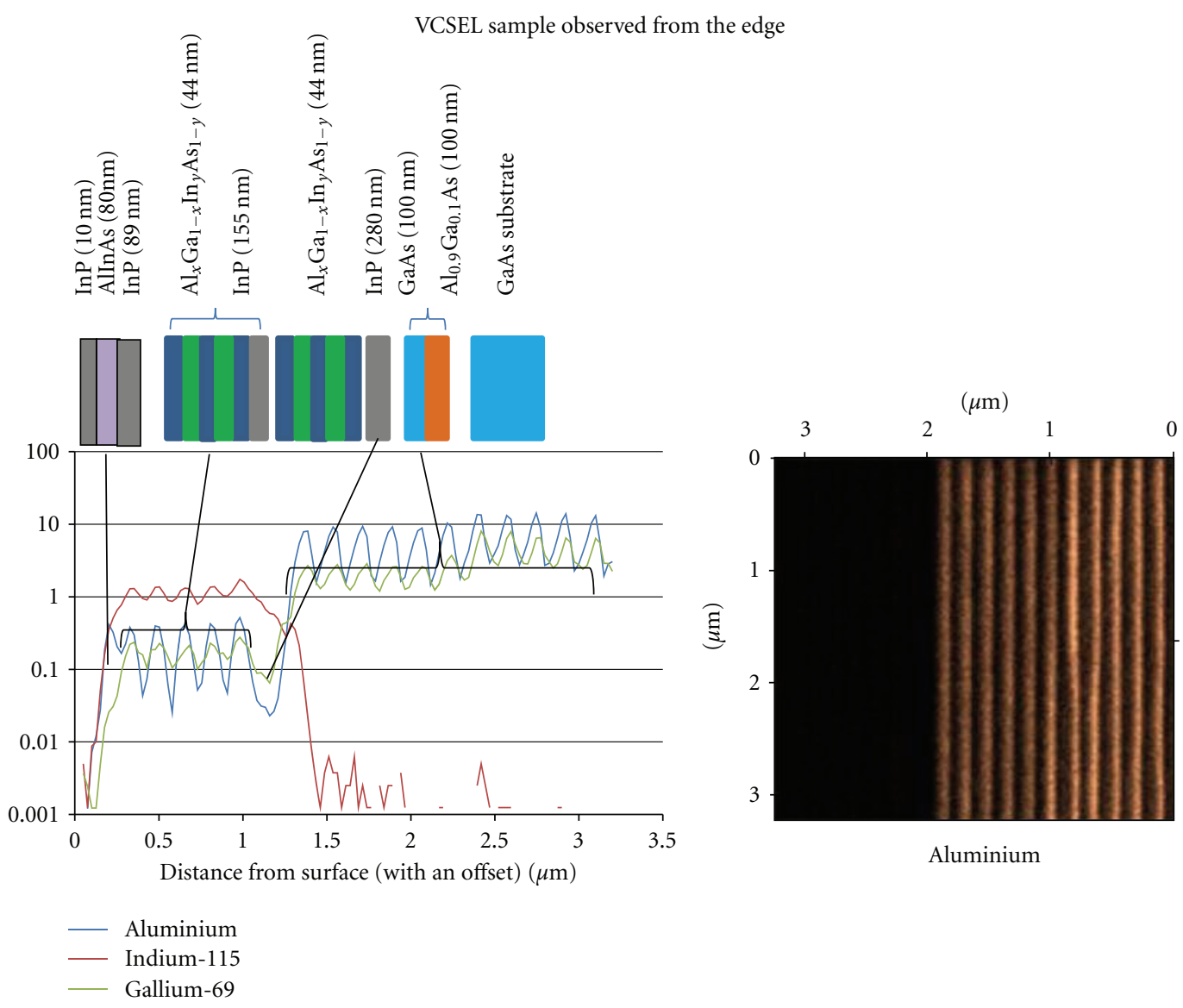

Figure 13: Side-on view of VECSEL 3/1 (see text). As for the depth profile, all features can be discerned, expect for the structure within each quantum well gain region (each $44 \mathrm{~nm}$ thick containing three $10 \mathrm{~nm}$ bands richer in aluminium). The $100 \mathrm{~nm}$ thick aluminium rich regions in the distributed Bragg reflector (right-hand side of figure and image) are well separated but do not have a flat-top. The lateral resolution is thus of the order of $100 \mathrm{~nm}$ in this example.

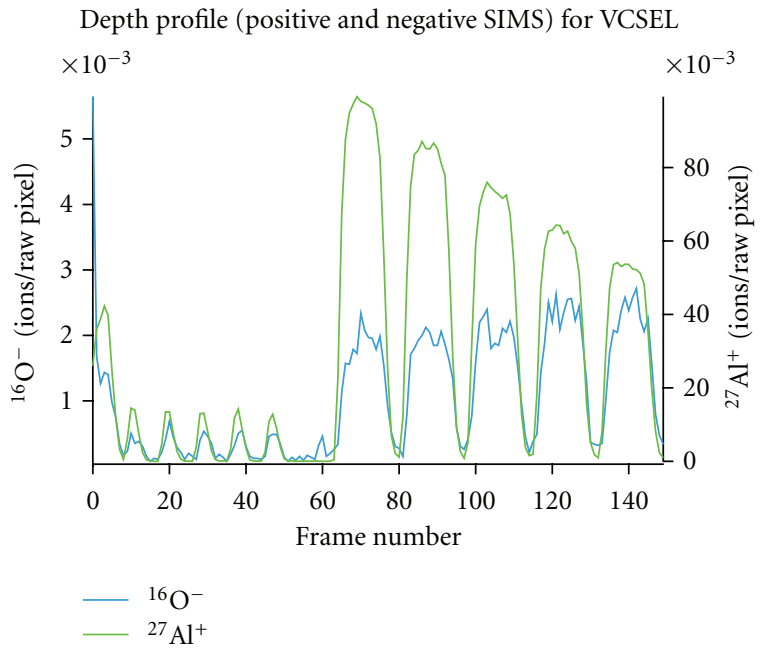

FIGURE 14: Overlay of depth profiles of aluminium and oxygen for VECSEL 3/1. Note the oxygen peak at frame 60, close to the interface between the two wafers. The smooth drop in the aluminium signals (not evident in Figure 12) was later discovered to be due to a temporary contamination of the ion optics. resolution of a secondary ion depth profile, given a sufficient signal to noise ratio, is in principle only limited by ioninduced mixing (usually of the order of a few nanometers but can be more depending on primary ion energy and angle and sample composition) and ion-induced roughening, in common with other techniques which use an ion beam to sputter away material in order to obtain a depth profile (e.g., XPS, Auger). Changes in the composition of the sample usually affect secondary ion yields, and differential sputtering (in the chemical sense rather than the topographical sense) will have an effect on depth profiles at interfaces [33]. The processes that limit SIMS depth resolution are discussed in detail in [34]. It is worth noting that we have no evidence for any background due to sputtered material being resputtered and ionised from the SIMS ion optics (i.e., no memory effect is detectable). Redeposition of material from the crater walls onto the crater floor can affect depth profiles [34,35], the extent to which this matters will depend upon the chemical structure of the sample, the size of the crater and the size and shape of the primary ion beam. With appropriate mathematical models, monolayer thicknesses can be reconstructed from SIMS depth profiles [36]. Note 


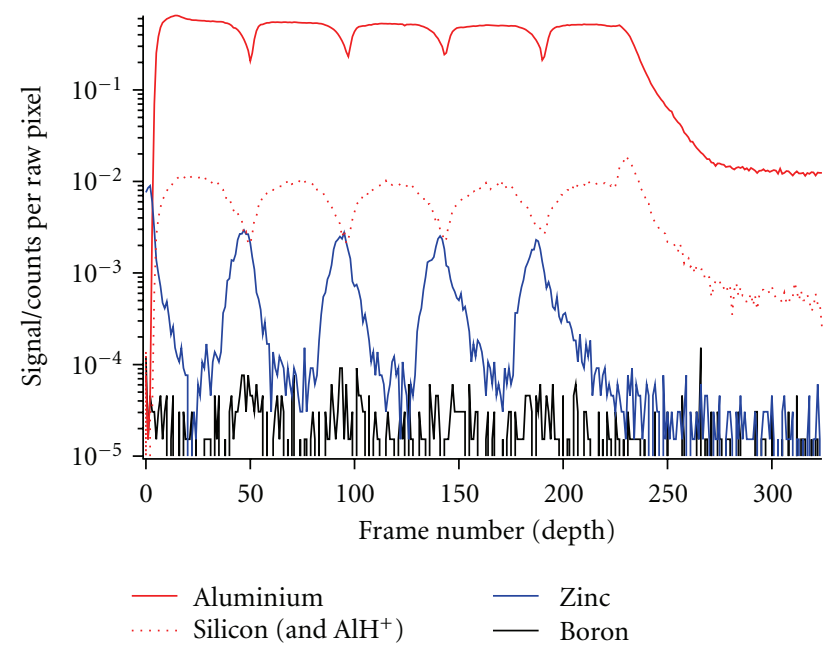

FIGURE 15: FIB-SIMS depth profile of ALD multilayer (five repeats of nominally $20 \mathrm{~nm}$ zinc oxide/ $20 \mathrm{~nm}$ aluminium oxide on a silicon substrate). $240 \mathrm{pA}, 5 \mathrm{keV}$ normally incident $\mathrm{Ga}+$ bombardment. For clarity, each trace is on a differently scaled linear vertical axis. The surface of the sample is to the left of the figure, the substrate to the right.

that the mixing-roughness-information depth (MRI) model proposed by Hofmann [36] ideally requires knowledge of the original surface topography, any interface topography, and of the sputtering induced roughness. A scanning probe microscope can provide at least two of these.

4.4. SPM-SIMS Integration. Because dynamic secondary ion measurements imply significant sputtering, in general ions originating from different depths will be measured at different times and thus the recorded dataset is in some sense three dimensional $[37,38]$. However, for heterogeneous samples there is no simple relationship between sputtering time or ion dose and the depth. This is because different materials and different crystal orientations will in general have different sputtering rates [39]. Furthermore, if the sample does not initially have a flat polished surface, then there will always be ambiguity about the spatial relationship between observed features as sputtering proceeds. Even for polished samples where the matrix is homogenous, surface roughening and swelling [40] due to the ion beam can distort the relationship between sputtering time or dose and the depth being sampled. Artefacts in the SIMS image may also arise due to imperfectly normal crater walls, because of edge effects when topography develops on the surface being measured and due to redeposition of sputtered atoms [35], and because local topography affects useful secondary ion yields [41]. For all of these reasons it is highly desirable to have available during sputtering a measurement of the surface profile relative to the original surface before sputtering commenced. The best way of doing this is to use a scanning probe microscope to measure the surface (other options such as stereo-pair electron beam imaging do not have sufficient depth resolution or accuracy; laser interferometry has been used to obtain sputtering rates [42] but gave no information on roughening or differential sputtering within a crater and can be difficult to interpret [43]). The use of an $e x$ situ SPM to improve SIMS 3D images has been previously described for example, by [31, 39, 44]. In situ measurements are highly desirable to increase the speed of measurements and to avoid concerns about contamination or reactions at the surface. This is however not commonplace because (i) few scanning probe microscopes are intended to work under vacuum, (ii) fewer still can easily be integrated with an electron microscope and focused ion beam (limited space, possible interactions), (iii) scanning probe microscopes are expensive, and (iv) combining SPM measurements with SIMS measurements can enormously increase the required measurement time. However, If an SPM is integrated with a SIMS measurement, then it opens up the possibility of not only sensing topography but also other properties of the surface (e.g., contact potential, magnetisation, and friction) complementary to the composition measured by SIMS. Because we had prior experience with SPM/SEM integration, it was natural to do some "proof of concept" experiments to demonstrate SPM/FIB/SEM-SIMS integration within a single vacuum chamber. We are unaware of any prior publications that show in situ SPM measurements of SIMS craters.

The in situ scanning probe microscope was developed together with SPECS Zurich GmbH. It utilised SmarAct$\mathrm{GmbH}$ positioners for coarse control of the tip and closedloop Nanodrive piezo stages from Mad City Labs Inc. for $\mathrm{z}$ tip control and $\mathrm{x}-\mathrm{y}$ fine positioning ( $\mathrm{x}-\mathrm{y}$ scanning was done by moving the sample rather than the probe tip). Frequency modulation atomic force microscopy (AFM) was performed with an Akiyama probe from Nanoworld AG [45]. A Nanonis SPM control system (base package and oscillation controller) was used for the probe amplitude and phase feedback loops, and to monitor the frequency shift of the probe. The geometry and self-sensing properties of the Akiyama probe are particularly well suited to a compact integration within the vacuum chamber close to the intersection of the charged particle beams with the sample. When not in use, the SPM probe tip was retracted from the measurement region using the coarse positioner, allowing free access of the charged particle beams to the sample, and unhindered collection of secondary ions and electrons. The SPM was mounted directly onto the sample stage of the FIB/SEM as shown in Figure 18. Although the Akiyama probe signal can be transduced in different ways, we illustrate here only the calculated $\mathrm{Z}$ displacement of the tip due to the surface being measured. The free software WSXM [46] was used to visualise and analyse the SPM datasets. An SPM scan in both directions over a $5 \times 5$ micron area typically took about 20 minutes (this obviously depends on the roughness, whether the crater edge is part of the scan, and the desired resolutions). The time to automatically withdraw the SPM tip so that FIB scanning can continue is about 15 seconds; more critical to combining the use of FIB-SIMS and SPM is the successful automatic coarse repositioning of the SPM tip.

The semiconductor laser sample described above was used as a test specimen. We were particularly interested to 

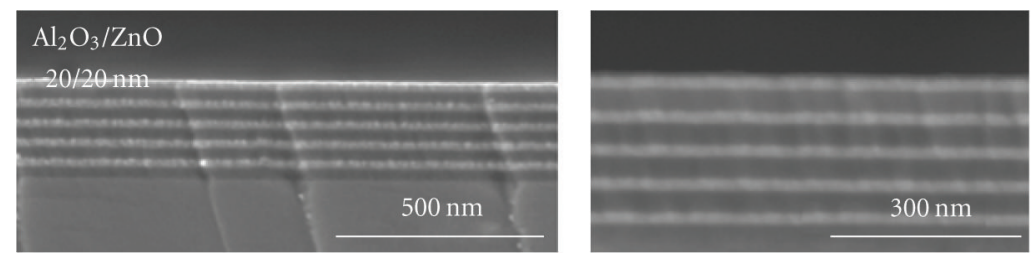

FIGURE 16: SEM image of the nominal $20 \mathrm{~nm} / 20 \mathrm{~nm}$ zinc oxide/aluminium oxide multilayer sample for which SIMS results are shown in Figure 15. The bright stripes are the zinc oxide layers, the dark stripes are the aluminium oxide layers, and the substrate is silicon. It can be seen that the zinc oxide layers are thinner than the aluminium oxide layers.

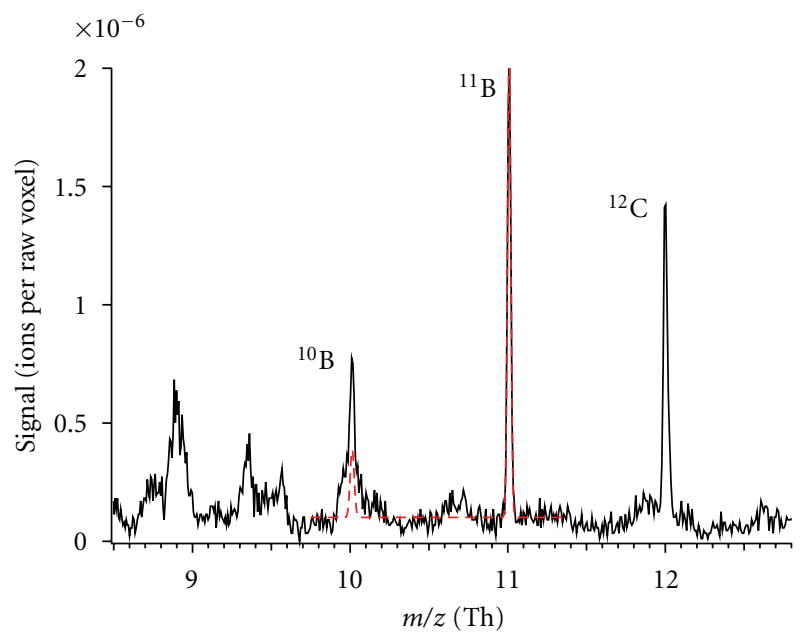

Figure 17: Part of the secondary ion mass spectrum from the multilayer zinc oxide/aluminium oxide ALD dataset shown in Figure 15. The red trace is a fit to boron with natural isotopic abundance, scaled and offset to the ${ }^{11} \mathrm{~B}^{+}$peak. The roughness in the baseline, and the apparent broad peaks below $10 \mathrm{Th}$ are due to electrical interference from the extraction pulse (boron rich samples show the expected isotope ratio more clearly). There are no possible isobaric interferences for boron, so the identification is unambiguous. The fitted ${ }^{10} \mathrm{~B}$ signal corresponds to about 350 detected ions in total.

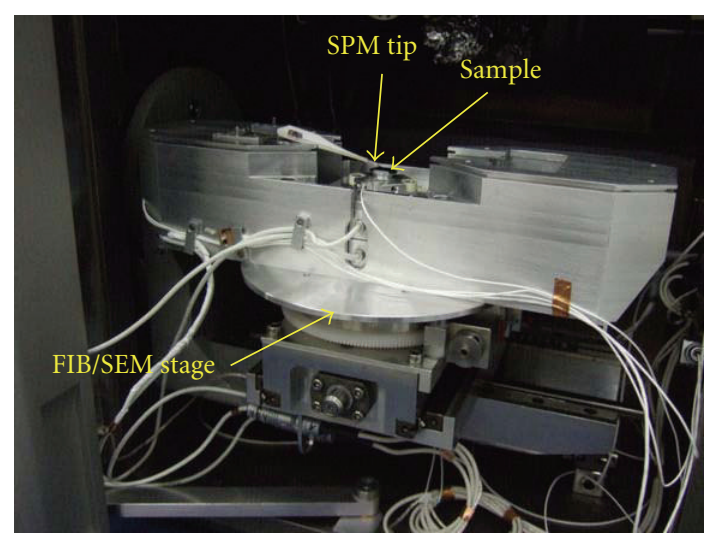

FIGURE 18: SPM tip and assembly in position on top of the FIB/SEM stage, with the stage in its "home" position. The SPM assembly is simply bolted to the stage. find out if surface roughening could have been affecting the depth resolution of the SIMS measurements. AFM scans were performed before, during, and after the SIMS measurement. ("during" meaning that the FIB beam was briefly turned off, and the AFM tip moved into position, before reverting to SIMS mode and continuing to sputter).

Figures 19 and 20 illustrate that the crater floor was fairly smooth (RMS roughness $4.9 \mathrm{~nm}$ at a depth of $750 \mathrm{~nm}$ after 200 frames), so ion-induced roughening cannot have been significantly limiting the extent to which the aluminiumrich stripes in the DBR were resolved although this degree of roughening will certainly have been detrimental to the resolution of the 7 and $10 \mathrm{~nm}$ deep features in the laser gain medium (quantum well structures). The crater walls, as imaged by the AFM, are not perfectly perpendicular to the sample surface, but there is little evidence for significant redeposition of material around the crater. It seems likely that the main reason for the unexpectedly poor modulation and resolution of the $100 \mathrm{~nm}$ thick aluminium structures is a combination of sputtering of redeposited material from within the crater and primary beam halo effects.

\section{Conclusions}

We have shown that it is possible to adapt a commercial FIB/SEM instrument for SIMS operation by adding a timeof-flight mass analyser without any detrimental effect upon normal operation. A depth resolution of $<20 \mathrm{~nm}$ and a lateral resolution of $<100 \mathrm{~nm}$ (see Figure 9) have been demonstrated (both for normally incident ions), and we expect to improve upon both of these figures in the near future. We have also demonstrated that the additional integration of a scanning probe microscope is possible, allowing true depth and roughness information to be obtained in series with SIMS measurements.

\section{Acknowledgments}

The authors gratefully acknowledge the financial support of the European Union for part of this work (FP7 Project FIBLYS, Grant Agreement no. CP-TP 214042-2) and funding from the Swiss Commission for Technology and Innovation with SPECS Zürich supporting the SEM/SPM development, (CTI-Project no. 9208.1 PFNM-NM). The authors would also like to thank Gerhard Bürki of EMPA for technical 


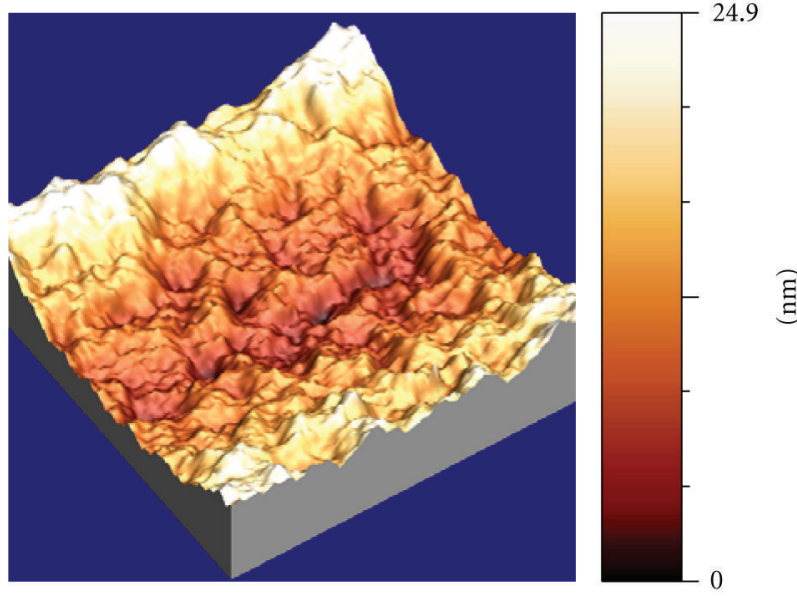

Figure 19: $5 \times 5 \mu \mathrm{m}$ SPM scan from within an FIB/SIMS crater after $20010 \times 10$ micron frames at $104 \mathrm{pA}$ and $20 \mathrm{kV} \mathrm{Ga}^{+}$. The RMS roughness is $4.9 \mathrm{~nm}$. The dataset has been corrected for global tilt. For a higher primary beam current of $401 \mathrm{pA}$ (similar to that used for the depth profiles and images shown above) RMS roughnesses of between 1 and $6 \mathrm{~nm}$ were measured.

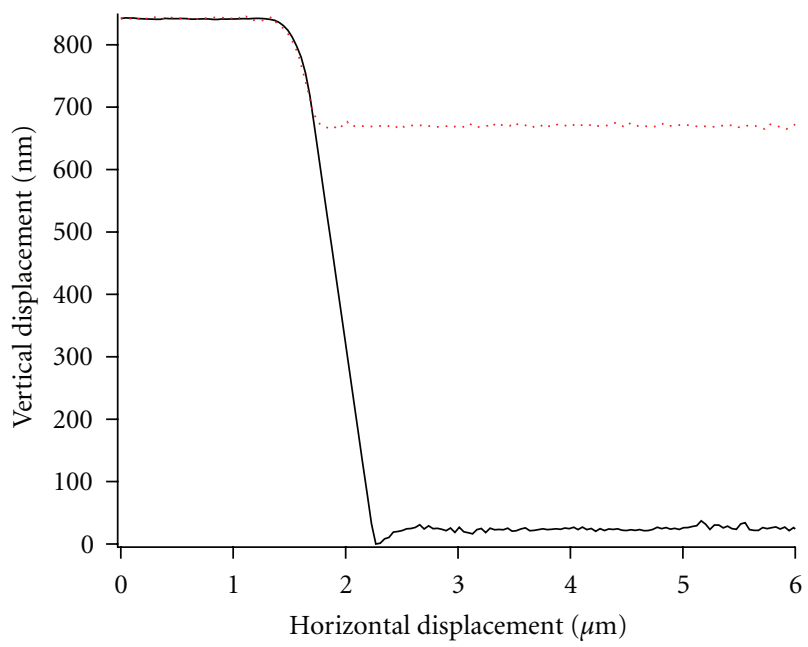

After 40 frames

— After 200 frames

FIGURE 20: SPM scans of the crater edge in semiconductor laser after 40 and 200 frames using $100 \mathrm{pA} 20 \mathrm{keV} \mathrm{Ga}^{+}$. The crater wall is not perfectly normal to the crater floor, but the slope remains constant as the crater becomes deeper.

assistance with the FIB/SEM and Dr V Iakovlev and Dr. A. Sirbu of EPFL for providing the VCSEL sample. For "Advances in Materials Science and Engineering" Dr. A. G. Balogh and an anonymous reviewer helped to improve the quality of this paper.

\section{References}

[1] C. A. Andersen and J. R. Hinthorne, "Ion microprobe mass analyzer," Science, vol. 175, no. 4024, pp. 853-860, 1972.
[2] R. Castain and G. Slodzian, "Optique corpusculaire-premiers essais de microanalyse par emission ionique secondaire," Comptes Rendus Hebdomadaires des Séances de l'Academie des Sciences, vol. 255, pp. 1893-1895, 1962.

[3] A. R. Bayly, A. R. Waugh, and K. Anderson, "SIMS microanalysis with a gallium ion microprobe," Nuclear Instruments and Methods In Physics Research, vol. 218, no. 1-3, pp. 375-382, 1983.

[4] J. M. Chabala, R. Levi-Setti, and Y. L. Wang, "Practical resolution limits of imaging microanalysis with a scanning ion microprobe," Applied Surface Science, vol. 32, no. 1-2, pp. 1032, 1988.

[5] D. N. Dunn and R. Hull, "Reconstruction of three-dimensional chemistry and geometry using focused ion beam microscopy," Applied Physics Letters, vol. 75, no. 21, pp. 34143416, 1999.

[6] L. B. Li, D. S. McPhail, N. Yakovlev, and H. Seng, "Strategies for improving the sensitivity of FIB-SIMS," Surface and Interface Analysis, vol. 43, pp. 495-497, 2011.

[7] G. Betz and F. Rüdenauer, "Collision cascade limit to spatial resolution in focused ion beam processes," Applied Surface Science, vol. 51, no. 1-2, pp. 103-112, 1991.

[8] D. S. McPhail, L. B. Li, R. J. Chater, N. Yakovlev, and H. Seng, "From FIB-SIMS to SIMS-FIB. The prospects for a $10 \mathrm{~nm}$ lateral resolution SIMS instrument with full FIB functionality," Surface and Interface Analysis, vol. 43, pp. 479483, 2011.

[9] M. Nojima, M. Toi, A. Maekawa et al., "Evaluation of the nano-beam SIMS apparatus," Applied Surface Science, vol. 231232, pp. 930-935, 2004.

[10] M. Senoner and W. E. S. Unger, "Lateral resolution of secondary ion mass spectrometry-results of an inter-laboratory comparison," Surface and Interface Analysis, vol. 39, no. 1, pp. 16-25, 2007.

[11] F. A. Stevie, "Focused ion beam secondary ion mass spectrometry (FIB-SIMS)," in Introduction to Focused Ion Beams, L. A. Gianuzzi and F. A. Stevie, Eds., chapter 13, Springer, New York, NY, USA, 2005.

[12] L. A. Giannuzzi and M. Utlaut, "A review of $\mathrm{Ga}^{+}$FIB/SIMS," Surface and Interface Analysis, vol. 43, pp. 475-478, 2010.

[13] R. G. Cooks and A. L. Rockwood, "The Thomson-a suggested unit for mass spectroscopists," Rapid Communications in Mass Spectrometry, vol. 5, p. 93, 1991.

[14] M. Guilhaus, "Principles and instrumentation in time-offlight mass spectrometry: physical and instrumental concepts," Journal of Mass Spectrometry, vol. 30, no. 11, pp. 15191532, 1995.

[15] A. Tempez, J. A. Schultz, S. Della-Negra et al., "Orthogonal time-of-flight secondary ion mass spectrometric analysis of peptides using large gold clusters as primary ions," Rapid Communications in Mass Spectrometry, vol. 18, no. 4, pp. 371376, 2004.

[16] I. S. Gilmore and M. P. Seah, "Ion detection efficiency in SIMS: dependencies on energy, mass and composition for microchannel plates used in mass spectrometry," International Journal of Mass Spectrometry, vol. 202, no. 1-3, pp. 217-229, 2000.

[17] HDF5 Group, http://www.hdfgroup.org

[18] H. N. Migeon, F. Saldi, Y. Gao, and M. Schuhmacher, "Ion microscope and ion microprobe analysis under oxygen, cesium and gallium bombardment," International Journal of Mass Spectrometry and Ion Processes, vol. 143, no. C, pp. 5163, 1995. 
[19] G. Frache, B. El Adib, J.-N. Audinot, and H.-N. Migeon, "Evaluation of ionization yields under gallium bombardment," Surface and Interface Analysis, vol. 43, pp. 639-642, 2010.

[20] L. A. Machlan, J. W. Gramlich, L. J. Powell, and G. M. Lambert, "Absolute isotopic abundance ratio and atomic weight of a reference sample of gallium," Journal of Research of the National Bureau of Standards, vol. 91, no. 6, pp. 323-331, 1986.

[21] J. Maul and K. Wittmaack, "Secondary ion emission from silicon and silicon oxide," Surface Science, vol. 47, no. 1, pp. 358-369, 1975.

[22] A. Licciardello, L. Renna, and S. Pignataro, "Interfacial phenomena during depth profiling with gallium ions: a ToFSIMS approach," Surface and Interface Analysis, vol. 30, no. 1, pp. 243-246, 2000.

[23] A. E. Morgan, H. A. M. de Grefte, N. Warmoltz, H. W. Werner, and H. J. Tolle, "The influence of bombardment conditions upon the sputtering and secondary ion yields of silicon," Applications of Surface Science, vol. 7, no. 4, pp. 372-392, 1981.

[24] P. C. Zalm and C. J. Vriezema, "The influence of bombardment conditions upon the sputtering and secondary ion yields of silicon," Nuclear Instruments and Methods in Physics Research, vol. 64, pp. 626-631, 1992.

[25] Y. Kudriavtsev, A. Villegas, A. Godines, and R. Asomoza, "SIMS analysis of residual gas elements with a Cameca IMS6f ion microprobe," Applied Surface Science, vol. 252, no. 10, pp. 3406-3412, 2006.

[26] T. Sakamoto, B. Tomiyasu, M. Owari, and Y. Nihei, "Ambient oxygen effect in $\mathrm{Ga}^{+}$FIB-SIMS," Surface and Interface Analysis, vol. 22, no. 1, pp. 106-110, 1994.

[27] T. Sakamoto, M. Owari, and Y. Nihei, "Behavior of gallium secondary ion intensity in gallium focused ion beam secondary ion mass spectrometry," Japanese Journal of Applied Physics Part 1, vol. 36, no. 3, pp. 1287-1291, 1997.

[28] M. Senoner, T. Wirth, and W. E. S. Unger, "Imaging surface analysis: lateral resolution and its relation to contrast and noise," Journal of Analytical Atomic Spectrometry, vol. 25, no. 9, pp. 1440-1452, 2010.

[29] ISO 181115: 2001, Surface Chemical Analysis-Vocabulary, ISO, Geneva, Switzerland.

[30] J. Lyytikäinen, J. Rautiainen, L. Toikkanen et al., “1.3- $\mu \mathrm{m}$ optically-pumped semiconductor disk laser by wafer fusion," Optics Express, vol. 17, no. 11, pp. 9047-9052, 2009.

[31] G. Friedbacher, D. Schwarzbach, P. K. Hansma, H. Nickel, M. Grasserbauer, and G. Stingeder, "A combination of atomic force microscopy and secondary ion mass spectrometry for investigation of AlxGa1-xAs/GaAs superlattices," Fresenius' Journal of Analytical Chemistry, vol. 345, no. 8-9, pp. 615-617, 1993.

[32] S. M. George, A. W. Ott, and J. W. Klaus, "Surface chemistry for atomic layer growth," Journal of Physical Chemistry, vol. 100, no. 31, pp. 13121-13131, 1996.

[33] H. H. Andersen, "The depth resolution of sputter profiling," Applied Physics, vol. 18, no. 2, pp. 131-140, 1979.

[34] C. W. Magee and R. E. Honig, "Depth profiling by SIMSdepth resolution, dynamic range and sensitivty," Surface and Interface Analysis, vol. 4, no. 2, pp. 35-41, 1982.

[35] F. G. Rüdenauer and W. Steiger, "Sputter redeposition as a limit to spatially three-dimensional SIMS microanalysis," Ultramicroscopy, vol. 24, no. 2-3, pp. 115-123, 1988.

[36] S. Hofmann, "Profile reconstruction in sputter depth profiling," Thin Solid Films, vol. 398-399, pp. 336-342, 2001.

[37] A. J. Patkin and G. H. Morrison, "Secondary ion mass spectrometric image depth profiling for three-dimensional ele- mental analysis," Analytical Chemistry, vol. 54, no. 1, pp. 2-5, 1982.

[38] R. G. Rudenauer, "Spatially multidimensional secondary ion mass spectrometry analysis," Analytica Chimica Acta, vol. 297, no. 1-2, pp. 197-230, 1994.

[39] M. L. Wagter, A. H. Clarke, K. F. Taylor, P. A. W. Van Der Heide, and N. S. McIntyre, "Topographic correction of 3D SIMS images," Surface and Interface Analysis, vol. 25, no. 10, pp. 788-789, 1997.

[40] H. Gnaser, A. Brodyanski, and B. Reuscher, "Focused ion beam implantation of $\mathrm{Ga}$ in $\mathrm{Si}$ and Ge: fluence-dependent retention and surface morphology," Surface and Interface Analysis, vol. 40, no. 11, pp. 1415-1422, 2008.

[41] R. Levi-Setti, J. M. Chabala, and Y. L. Wang, "Aspects of high resolution imaging with a scanning ion microprobe," Ultramicroscopy, vol. 24, no. 2-3, pp. 97-113, 1988.

[42] E. De Chambost, P. Monsallut, B. Rasser, and M. Schuhmacher, "Depth scale calibration of SIMS depth profiles by means of an online crater depth measurement technique," Applied Surface Science, vol. 203-204, pp. 391-395, 2003.

[43] P. A. Ronsheim, R. Loesing, and A. Madan, "Sputtered depth scales of multi-layered samples with in situ laser interferometry: arsenic diffusion in Si/SiGe layers," Applied Surface Science, vol. 231-232, pp. 762-767, 2004.

[44] A. Wucher, J. Cheng, L. Zheng, D. Willingham, and N. Winograd, "Three-dimensional molecular imaging using mass spectrometry and atomic force microscopy," Applied Surface Science, vol. 255, no. 4, pp. 984-986, 2008.

[45] T. Akiyama, U. Staufer, and N. F. De Rooij, "Self-sensing and self-actuating probe based on quartz tuning fork combined with microfabricated cantilever for dynamic mode atomic force microscopy," Applied Surface Science, vol. 210, no. 1-2, pp. 18-21, 2003.

[46] I. Horcas, R. Fernández, J. M. Gómez-Rodríguez, J. Colchero, J. Gómez-Herrero, and A. M. Baro, "WSXM: a software for scanning probe microscopy and a tool for nanotechnology," Review of Scientific Instruments, vol. 78, no. 1, Article ID 013705, 2007. 

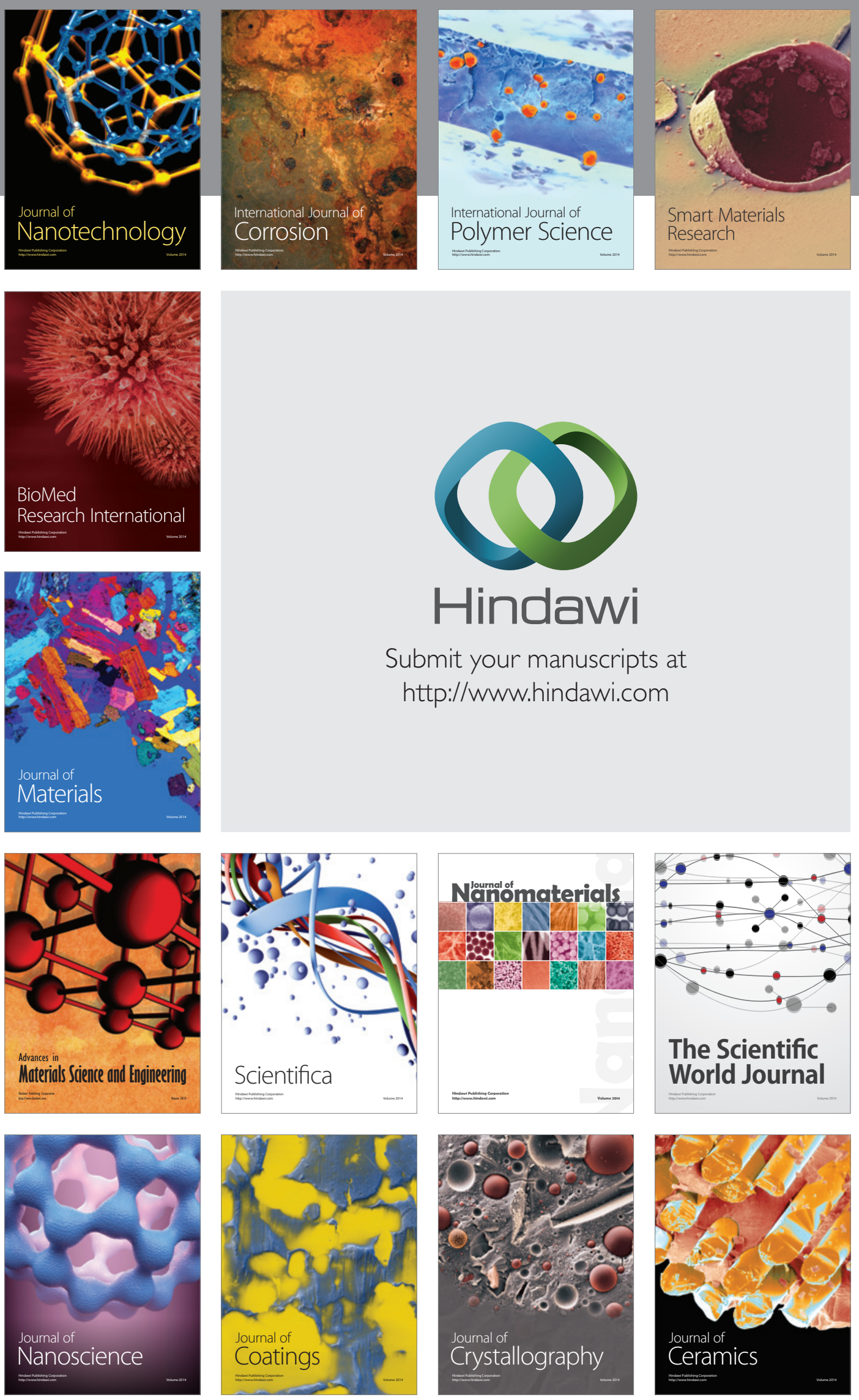

The Scientific World Journal

Submit your manuscripts at

http://www.hindawi.com

\section{World Journal}

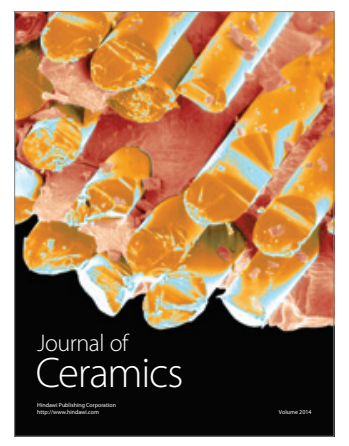

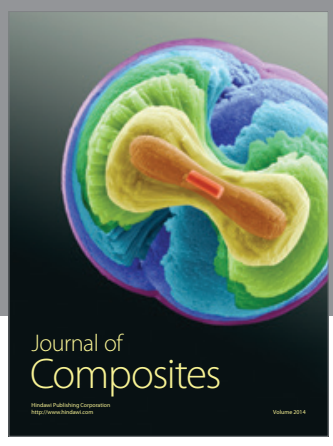
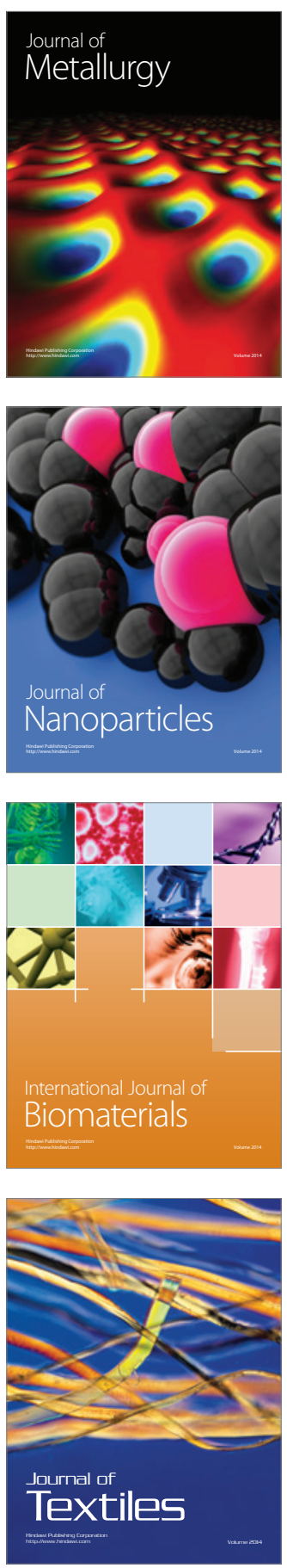